\title{
Studying the Attribution of LiF in OLED by the $C-V$ Characteristics
}

\author{
Chun-lin Zhang, ${ }^{1,2}$ Fang-cong Wang, ${ }^{1}$ Yong Zhang, ${ }^{3}$ Hai-xia Li, ${ }^{4}$ and Su Liu1 \\ ${ }^{1}$ Institute of Microelectronics, School of Physical Science and Technology, Lanzhou University, Lanzhou City 730000, China \\ ${ }^{2}$ School of Mathematics, Physics and Software Engineering, Lanzhou Jiaotong University, Lanzhou University, Lanzhou 730070, China \\ ${ }^{3}$ Editorial Board of Journal of Lanzhou University, Lanzhou 730000, China \\ ${ }^{4}$ Institute of Modern Physics, Chinese Academy of Sciences, Lanzhou 73000, China
}

Correspondence should be addressed to Su Liu, liusu@lzu.edu.cn

Received 31 July 2010; Revised 30 October 2010; Accepted 1 November 2010

Academic Editor: Fahrettin Yakuphanoglu

Copyright () 2010 Chun-lin Zhang et al. This is an open access article distributed under the Creative Commons Attribution License, which permits unrestricted use, distribution, and reproduction in any medium, provided the original work is properly cited.

\begin{abstract}
The organic light-emitting device (OLED) with simple structures of indium tin oxide (ITO)/tris(8-quinolinolato) aluminum $\left(\mathrm{Alq}_{3}\right) / \mathrm{LiF} / \mathrm{Al}$ and ITO/Alq $3 / \mathrm{Al}$ was fabricated to analyze the contribution of $\mathrm{LiF}$ in OLED. We used the $C-V$ characteristics to investigate the contribution of LiF in OLED and found that the capacitance of the above-mentioned structures was $12.5 \mathrm{nF}$ and $77.5 \mathrm{nF}$, respectively. It is shown that the LiF layer affects the property of OLED resulting in the change of the capacitance of the device.
\end{abstract}

\section{Introduction}

$C-V$ Since the OLED was developed, the OLED has been considered as a promising candidate for full-color, flat panel display because of its prominent advantages, such as simplicity in fabrication and convenience in application [1]. Much effort has been made to improve the performance of the device. It is known that the performance of OLED depends heavily on the efficiency of carriers injection and their recombination, which generates molecular excitons, as well as the balance between the holes and electrons [2]. In order to achieve maximal efficiency, we hold the view that it is essential that more electrons should be injected into the emission layer.

However, since electron mobility is much lower than hole mobility, OLED has a fatal problem for applications due to its relatively low efficiency in comparison with other competitive displays. It is generally considered that the balanced carriers are desirable for high electroluminescence (EL) efficiency, low operation voltage, and high brightness. So, finding a way of increasing the number of electrons or reducing the number of holes which could reach the cathode is considered as one of the most direct and economic solutions to improve the efficiency of the device.

So far, there have been several approaches to increase the number of injected electrons including modification of the cathode contact and electron transport layer, which has been known to improve carriers' balance and recombination $[3,4]$. One of the simplest and often-used methods is to insert a buffer layer as the electron-injection layer (EIL), such as the inorganic $\mathrm{LiF}$ [5], $\mathrm{CsF}[6], \mathrm{NaCl}$ [7], $\mathrm{NaF}$ [8], $\mathrm{Al}_{2} \mathrm{O}_{3}$ [9], $\mathrm{SiO}_{2}$, and $\mathrm{MgO}$, between an emitting layer (EL) and the cathode, this can improve the device efficiency and stability [10]. In contrast to the conventional view that the existence of such an extra insulating layer might increase the turn-on voltage a significant decrease in turn-on voltage is usually observed in the OLED if such a buffer layer is used. The reason lies in that effective energy barrier has been reduced because of the increased charges injection [11-13] and the presence of low work-function metal following the chemical reaction of buffer materials [14]. In fact, the low work-function metal is usually neglected when we consider the energy barrier between the metal and other materials, because its contribution can be ignored. 
In this paper, the authors demonstrated the contribution of such a buffer layer which can significantly improve the device performance by increasing the number of injected electrons and reducing the number of holes which could reach the cathode.

\section{Experimental Details}

In our experiment, the standard OLED was fabricated and the ITO-coated glass substrates with a sheet resistance of about $30 \Omega /$ sq and the thickness of $150 \mathrm{~nm}$ were supplied by South Glass, Ltd. The OLED was made by following process. First, ITO-coated glasses were cleaned by using acetone, alcohol, and deionized water in an ultrasonic bath at $60^{\circ} \mathrm{C}$ for 20 minutes and dried by using $\mathrm{N}_{2}$ gas with a purity of 99.99\%. Second, the films of $\mathrm{Alq}_{3}$ and LiF were sequentially grown on ITO-coated glass by thermal evaporation under high vacuum with $3 \times 10^{-3} \mathrm{~Pa}$ at room temperature, and the growth rate of $\mathrm{Alq}_{3}$ was $0.1 \mathrm{~nm} / \mathrm{s}$ and that of $\mathrm{LiF}$ was $0.02 \mathrm{~nm} / \mathrm{s}$. Finally, Al metal was evaporated on $\mathrm{Alq}_{3}$ or $\mathrm{LiF} / \mathrm{Alq}_{3}$ film at the rate of $0.5 \mathrm{~nm} / \mathrm{s}$. The thickness of the films was controlled by a quartz thickness monitor.

In this research, the purity of $\mathrm{LiF}$ was $99.99 \%$, and the following two structures were fabricated:

Type A: Al $(110 \mathrm{~nm}) / \mathrm{LiF}(1 \mathrm{~nm}) / \mathrm{Alq}_{3}(65 \mathrm{~nm}) / \mathrm{ITO}$ $(150 \mathrm{~nm})$,

type B: Al (110 nm)/Alq 3 (65 nm)/ITO (150 nm).

Their capacitance-voltage $(C-V)$ was measured by KEITHLEY 4200, at the same time, we measured their current density-voltage $(J-V)$ and Luminescence-Voltage $(L-$ $V$ ) characteristics by KEITHELY 228A and ST-86LA spot photometer, respectively. All the measurements were done under ambient conditions without encapsulation.

\section{Results and Discussion}

According to the classical theory [15], the junction capacitance is

$$
C=\frac{\varepsilon \cdot S}{W} .
$$

To type A, the capacitance is

$$
\begin{aligned}
& \frac{1}{C_{\mathrm{A}}}=\frac{1}{C_{\mathrm{Alq}_{3}}}+\frac{1}{C_{\mathrm{LiF}}} \\
& \Longrightarrow C_{\mathrm{A}}=\frac{C_{\mathrm{Alq}_{3}} \cdot C_{\mathrm{LiF}}}{C_{\mathrm{Alq}_{3}}+C_{\mathrm{LiF}}} .
\end{aligned}
$$

To type $B$, the capacitance is

$$
C_{\mathrm{B}}=C_{\mathrm{Alq}_{3}} \text {. }
$$

To the $\mathrm{Alq}_{3}$ layer, the capacitance is

$$
C_{\mathrm{Alq}_{3}}=\frac{\varepsilon_{\mathrm{Alq}_{3}} S}{W} .
$$

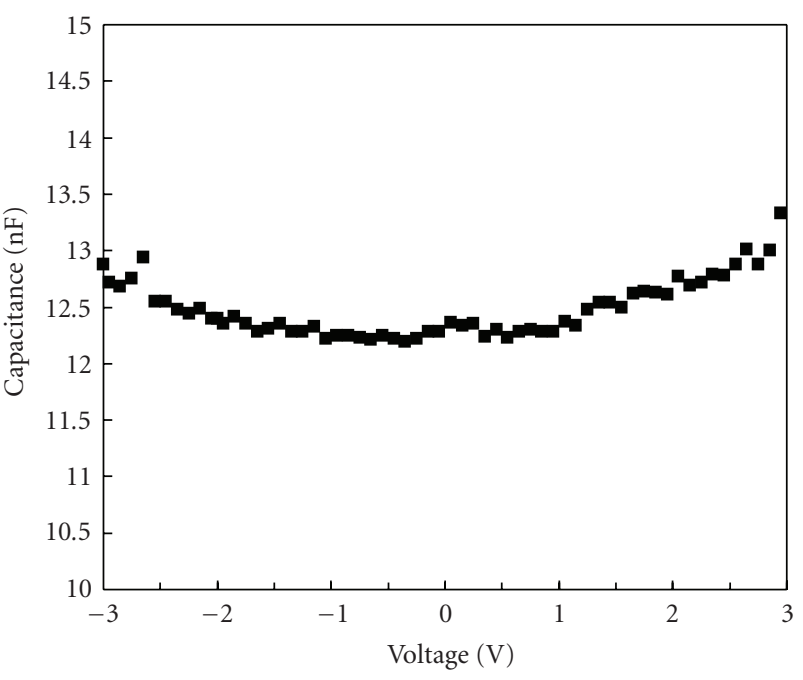

Figure 1: The $C-V$ characteristics of the device with the structure of ITO/Alq $3 / \mathrm{LiF} / \mathrm{Al}$.

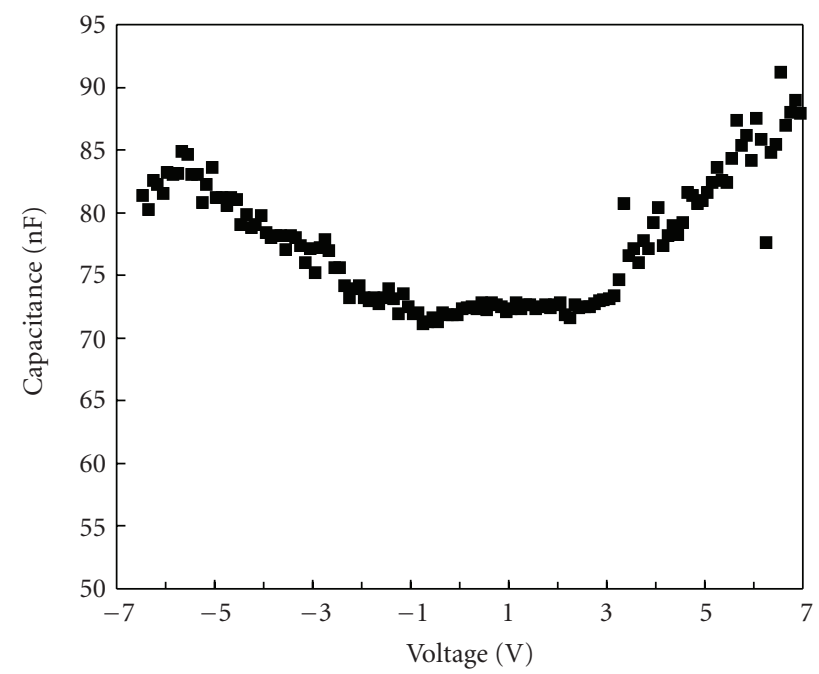

FIgure 2: The $C-V$ characteristics of the device with the structure of ITO/Alq $/ \mathrm{Al}$.

To the LiF layer, the capacitance is

$$
C_{\mathrm{LiF}}=\frac{\varepsilon_{\mathrm{LiF}} S}{W} .
$$

According to (4) and (5), it is obviously obtained that the $C_{\mathrm{Alq}_{3}}$ is smaller than the $C_{\mathrm{LiF}}$, because the thickness $W$ of the films of $\mathrm{Alq}_{3}$ and $\mathrm{LiF}$ is $65 \mathrm{~nm}$ and $1 \mathrm{~nm}$, respectively; $\mathrm{Alq}_{3}$ is an organic semiconducting material; $\mathrm{LiF}$ is an insulating material, so the dielectric constant $\varepsilon$ of the $\mathrm{Alq}_{3}$ is smaller than that of the LiF.

From Figures 1 and 2, we could get that the capacitance of type $\mathrm{A}$ and $\mathrm{B}$ is $12.5 \mathrm{nF}$ and $77.5 \mathrm{nF}$, respectively. So there must be a reaction between the insulating layer $(\mathrm{LiF})$ and the active layer $\left(\mathrm{Alq}_{3}\right)$, or we could not get the result that the $C_{A}$ is smaller than the $C_{\mathrm{B}}$. Here the capacitance of $\mathrm{Alq}_{3}$ is much smaller 


\begin{tabular}{|c|c|c|c|c|c|}
\hline ITO & $\mathrm{Alq}_{3}$ & $\begin{array}{c}\mathrm{Alq}_{3} \\
\left(\mathrm{~F}^{-}\right)\end{array}$ & $\begin{array}{c}\mathrm{Alq}_{3} \\
\left(\mathrm{Li}^{+}\right)\end{array}$ & $\mathrm{LiF}$ & $\mathrm{Al}$ \\
\hline
\end{tabular}

FIGURE 3: The inner structure of the device of ITO/Alq $3 / \mathrm{LiF} / \mathrm{Al}$.

than that of the LiF; hence we could ignore the capacitance of the $\mathrm{LiF}$ layer. Because the $C_{\mathrm{A}}$ is much smaller than the $C_{B}$, we could get that the $\varepsilon\left[\mathrm{LiF}(1 \mathrm{~nm}) / \mathrm{Alq}_{3}\right.$ $(65 \mathrm{~nm})]$ is smaller than the $\varepsilon\left[\mathrm{Alq}_{3}(65 \mathrm{~nm})\right]$. So the number of the injected electrons in the devices with LiF layer is much more than that in the device without the LiF layer, and the electrons could be injected continually to the $\mathrm{Alq}_{3}$ layer to protract the life of the OLED.

We could also obtain that the film of $\mathrm{Alq}_{3}$ must be separated into three parts, and just like Figure 3 shows, the $\mathrm{Alq}_{3}$ of the blank zone which is far from the LiF layer keeps its nature while the $\mathrm{Alq}_{3}$ of the shadow zone has been changed. There is a reaction between the $\mathrm{Alq}_{3}$ and the $\mathrm{LiF}$ here. Once the high electric field was given to the device, the $\mathrm{LiF}$ would be separated into $\mathrm{Li}^{+}$and $\mathrm{F}^{-}$and the $\mathrm{Li}^{+}$ would stay in the area which is close to the cathode in the shadow zone, while the $\mathrm{F}^{-}$would be pushed to the area which is far from the cathode in the shadow zone. The area with $\mathrm{Li}^{+}$where there must be more free carriers becomes well conductive, and the area with $\mathrm{F}^{-}$where there must be less free carriers becomes well insulating for electrons. The number of injected and transported electrons which could reach the emitting zone was increased. The balance of the injected holes from the anode and the injected electrons was well kept. The holes which could reach to the cathode were reduced because the area with $\mathrm{Li}^{+}$has changed into the conductive layer, and it would stop the holes to the largest extent. There were no more waste holes, and no more annihilation phenomenon occured. Most of the excitations would be only produced in the film of $\mathrm{Alq}_{3}$. The result was that the operation voltage and the luminance could be obviously improved.

The $J-V$ characteristics of the two types of devices are shown in Figure 4. The current density of type B at the same driving voltage is smaller than that of type $A$ as shown in the example that the turn-on voltage is $11 \mathrm{~V}$ for type $\mathrm{A}$, and $9 \mathrm{~V}$ for type B. Figure 5 shows the luminance measured as a function of voltage for the two types of devices. The luminance of type $\mathrm{A}$ at $16 \mathrm{~V}\left(1718 \mathrm{~cd} / \mathrm{m}^{2}\right)$ is higher than that of type $\mathrm{B}\left(1250 \mathrm{~cd} / \mathrm{m}^{2}\right)$. The improvement in luminance and operation voltage with $\mathrm{LiF}$ between the $\mathrm{Alq}_{3}$ and $\mathrm{Al}$ may be attributed to an enhanced balance of the holes and electrons. Electrons possessed a much lower mobility than holes in the organic materials [16]; this gives rise to an accumulation of excess holes at the ITO/Alq 3 boundary, and either increasing the number of electrons or decreasing the number of holes may help to improve the situation obviously. The presence of a $\mathrm{LiF}$ layer at the organic- $\mathrm{Al}$ interface can further reduce the barrier height for electron injection from the cathode, and it can enhance the performance of OLED.

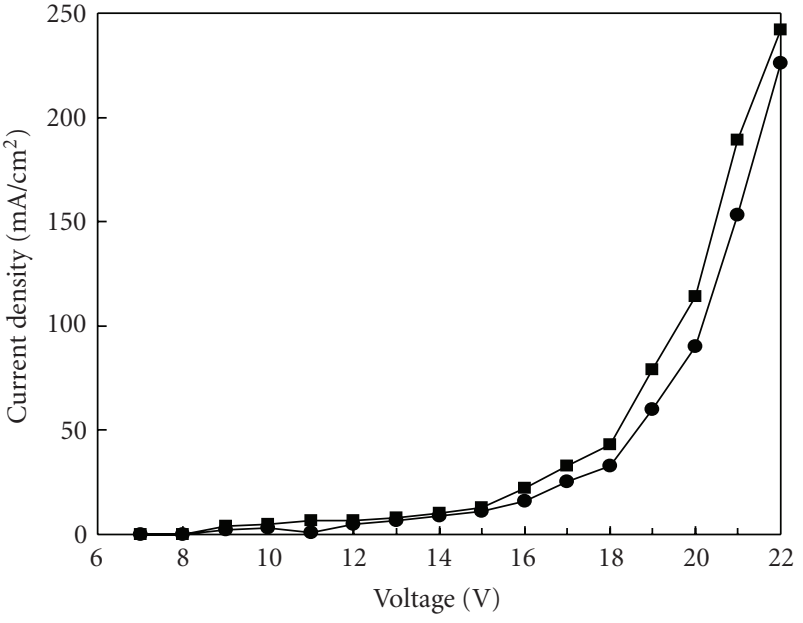

- The type $\mathrm{A}$

- The type B

FIgure 4: The $J-V$ characteristics for $\mathrm{ITO} / \mathrm{Alq}_{3} / \mathrm{LiF} / \mathrm{Al}$ (squares) and $\mathrm{ITO} / \mathrm{Alq}_{3} / \mathrm{Al}$ (circles) devices.

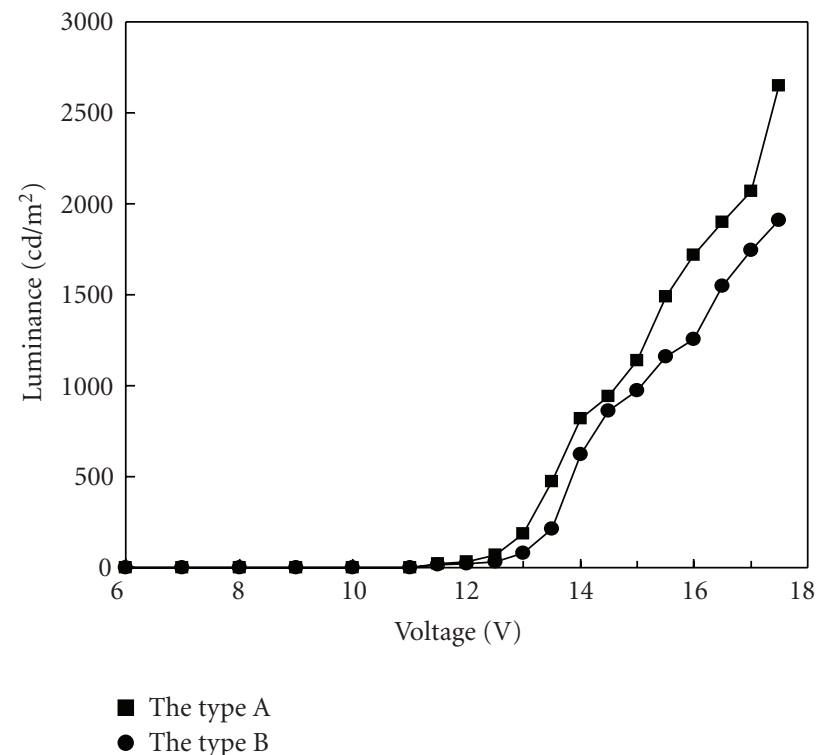

Figure 5: The $L-V$ characteristics for ITO/Alq $/ \mathrm{LiF} / \mathrm{Al}$ (squares) and ITO/Alq $/$ / Al (circles) devices.

\section{Conclusions}

In conclusion, we have succeeded in explaining what the insulating layers such as a LiF layer contributes in the OLED by using the $C-V$ characteristics. There is a reaction between the $\mathrm{Alq}_{3}$ and the $\mathrm{LiF}$, and the film of $\mathrm{Alq}_{3}$ is separated into three parts: the area which is close to the cathode is full of $\mathrm{Li}^{+}$, so this area becomes well conductive; the area which is far from the cathode is full of $\mathrm{F}^{-}$, so this area becomes well insulting. It indicates that the number of injected and transported electrons to the emitting zone is increased, and the number of holes which can reach to the cathode 
is reduced. Such an insulating layer with high dielectric constant results in not only such an evident increase in luminance but also the decreasing of the turn-on voltage of the device.

\section{References}

[1] C. W. Tang and S. A. Van Slyke, "Organic electroluminescent diodes," Applied Physics Letters, vol. 51, no. 12, pp. 913-915, 1987.

[2] N. C. Greenham, S. C. Moratti, D. D. C. Bradley, R. H. Friend, and A. B. Holmes, "Efficient light-emitting diodes based on polymers with high electron affinities," Nature, vol. 365, no. 6447, pp. 628-630, 1993.

[3] L. S. Hung, C. W. Tang, and M. G. Mason, "Enhanced electron injection in organic electroluminescence devices using an Al/LiF electrode," Applied Physics Letters, vol. 70, no. 2, pp. 152-154, 1997.

[4] S. Naka, H. Okada, H. Onnagawa, and T. Tsutsui, "High electron mobility in bathophenanthroline," Applied Physics Letters, vol. 76, no. 2, pp. 197-199, 2000.

[5] D. Grozea, A. Turak, X. D. Feng, and Z. H. Lu, "Chemical structure of $\mathrm{Al} / \mathrm{LiF} / \mathrm{Alq}$ interfaces in organic light-emitting diodes," Applied Physics Letters, vol. 81, no. 17, pp. 3173-3175, 2002.

[6] G. E. Jabbour, B. Kippelen, N. R. Armstrong, and N. Peyghambarian, "Aluminum based cathode structure for enhanced electron injection in electroluminescent organic devices," Applied Physics Letters, vol. 73, no. 9, pp. 1185-1187, 1998.

[7] S. J. Kang, D. S. Park, S. Y. Kim, C. N. Whang, K. Jeong, and S. $\mathrm{Im}$, "Enhancing the electroluminescent properties of organic light-emitting devices using a thin $\mathrm{NaCl}$ layer," Applied Physics Letters, vol. 81, no. 14, pp. 2581-2583, 2002.

[8] J. Lee, Y. Park, D. Y. Kim, H. Y. Chu, H. Lee, and L. -M. Do, "High efficiency organic light-emitting devices with $\mathrm{Al} / \mathrm{NaF}$ cathode," Applied Physics Letters, vol. 82, no. 2, pp. 173-175, 2003.

[9] S. J. Yun, Y. W. Ko, and J. W. Lim, "Passivation of organic light-emitting diodes with aluminum oxide thin films grown by plasma-enhanced atomic layer deposition," Applied Physics Letters, vol. 85, no. 21, pp. 4896-4898, 2004.

[10] T. Wakimoto, Y. Fukuda, K. Nagayama, A. Yokoi, H. Nakada, and M. Tsuchida, "Organic EL cells using alkaline metal compounds as electron injection materials," IEEE Transactions on Electron Devices, vol. 44, no. 8, pp. 1245-1248, 1997.

[11] Y. E. Kim, H. Park, and J. J. Kim, "Enhanced quantum efficiency in polymer electroluminescence devices by inserting a tunneling barrier formed by Langmuir-Blodgett films," Applied Physics Letters, vol. 69, no. 5, pp. 599-601, 1996.

[12] S. H. Kim, J. Jang, and J. Y. Lee, "Improvement in power efficiency in organic light emitting diodes through intermediate Mg:Ag layer in Li/FMg:Ag/Al cathodes," Electrochemical and Solid-State Letters, vol. 10, no. 10, pp. J117-J119, 2007.

[13] E. Zhou, Z. Deng, Z. Lv, Z. Chen, D. Xu, and Y. Wang, "Enhancing properties of organic light-emitting diodes with LiF inside the hole transport layer," Current Applied Physics, vol. 9, no. 6, pp. 1365-1368, 2009.

[14] L. S. Hung, R. Q. Zhang, P. He, and G. Mason, "Contact formation of $\mathrm{LiF} / \mathrm{Al}$ cathodes in Alq-based organic lightemitting diodes," Journal of Physics D, vol. 35, no. 2, pp. 103107, 2002.

[15] M. Shi, Semiconductor Devices: Physics and Technology, Suzhou University Press, Suzhou, China, 2nd edition, 2002.
[16] S. Naka, H. Okada, H. Onnagawa, J. Kido, and T. Tsutsui, "Time-of-flight measurement of hole mobility in aluminum (III) complexes," Japanese Journal of Applied Physics, vol. 38, no. 11, pp. L1252-L1254, 1999. 


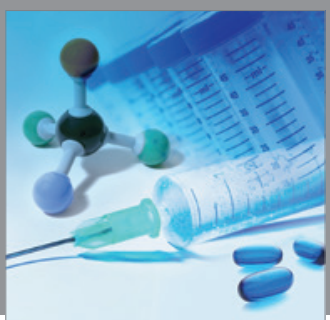

International Journal of

Medicinal Chemistry

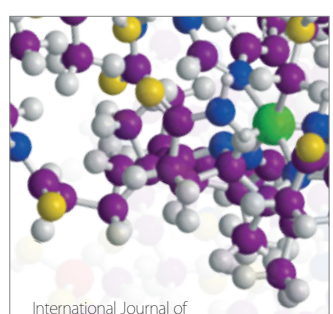

Carbohydrate Chemistry

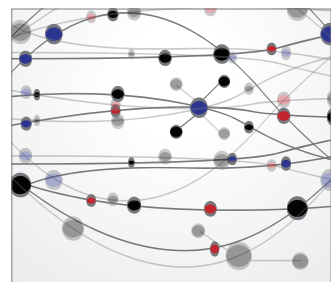

The Scientific World Journal
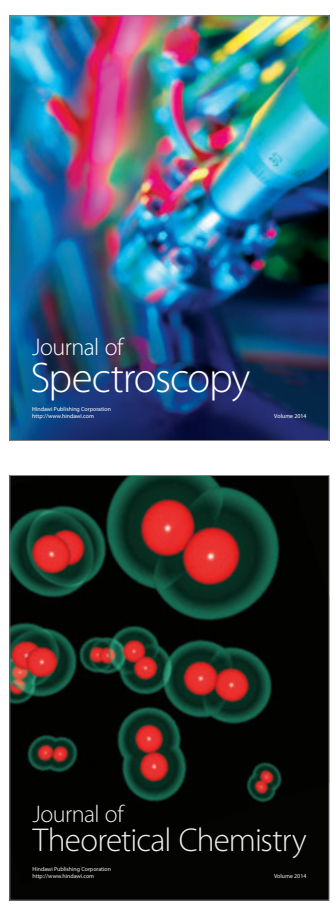
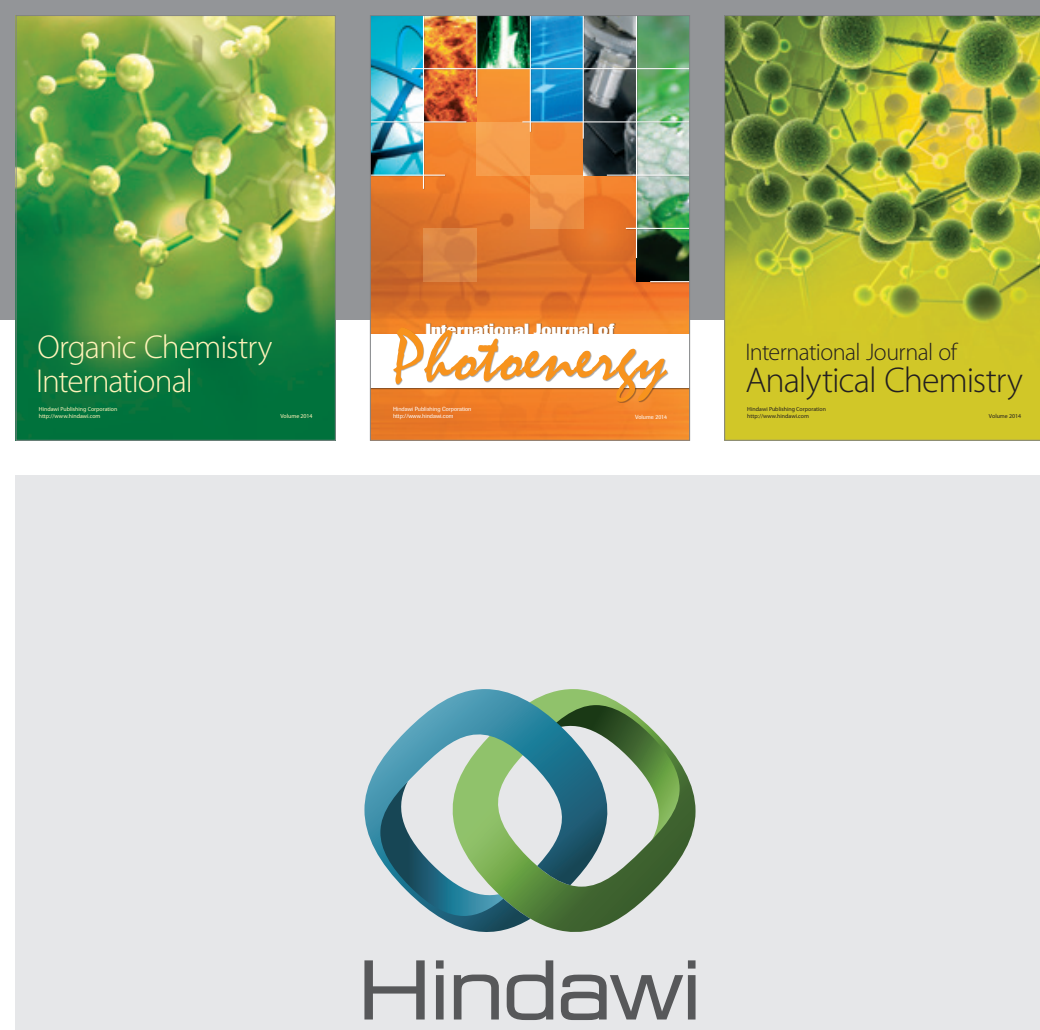

Submit your manuscripts at

http://www.hindawi.com
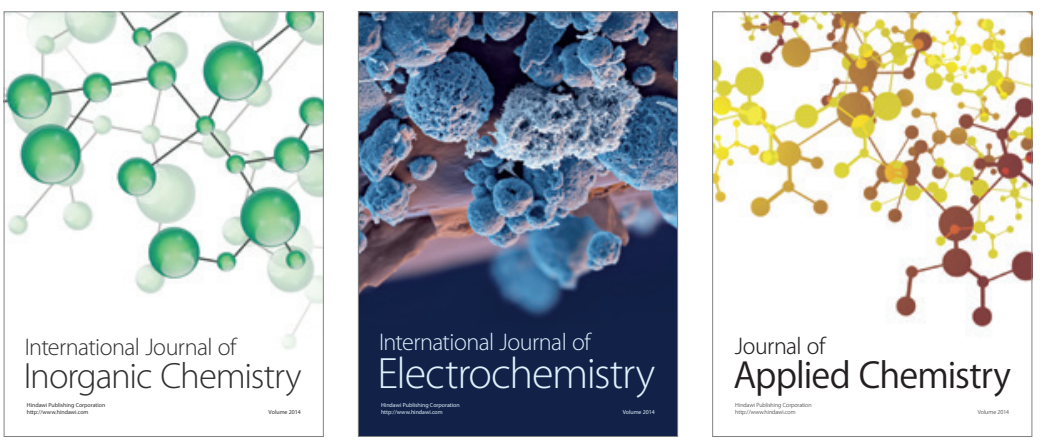

Journal of

Applied Chemistry
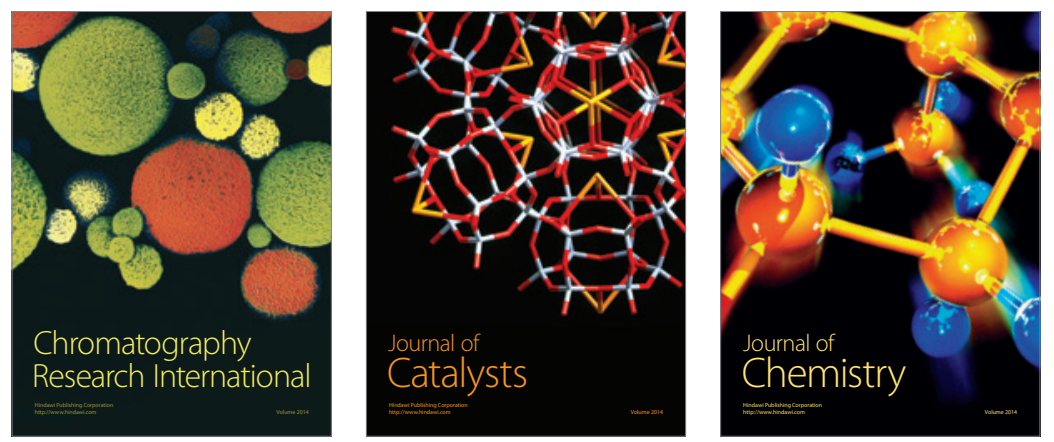
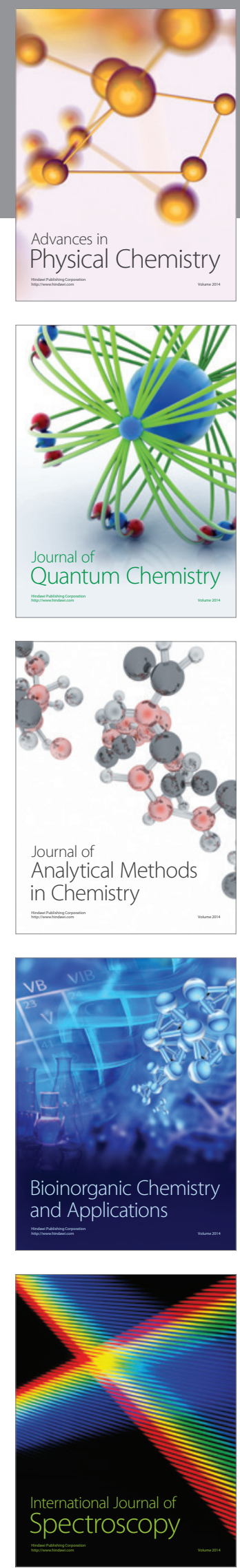